S.O. Rudchenko, A.T. Pugachov, V.E. Pukha, V.V. Starikov, S.N. Lavrynenko and A.G. Mamalis

\title{
Carbon films for photovoltaic devices
}

ABSTRACT. The results of structural, mechanical and optical investigations of thin $\mathrm{C}_{60}$ and diamond-like carbon (DLC) films, considered as functional layers for photovoltaic converters, are presented. The absorption spectra are calculated and the optical band gaps of $\mathrm{C}_{60}$ and DLC films are determined based on experimentally obtained transmission and reflexion data. The multilayer system ITO/DLC/C $\mathrm{C}_{60} / \mathrm{Al}$ demonstrating a photovoltaic effect was synthesized and researched.

Keywords: absorption coefficient, band gap, current-voltage characteristics, diamond-like carbon film, fullerene

Nanotechnology Perceptions 9 (2013) 159-166

Nonsubscribers: purchase individual article 